\title{
STUDI PENGARUH PENAMBAHAN TIMAH HITAM TERHADAP STRUKTUR KRISTAL LAPISAN TIPIS PZT DI DAERAH MORPHOTROPIC PHASE BOUNDARY (MPB)
}

\author{
Titus Lapailaka- $1^{1}$, Rachmat Triandi Tjahjanto ${ }^{1}$, dan Masruroh $^{2}$ \\ ${ }^{1}$ Jurusan Kimia, Fakutas Matematika dan Ilmu Pengetahuan Alam, \\ Universitas Brawijaya, Jalan VeteranMalang 65145, Jawa Timur, Indonesia \\ ${ }^{2}$ Jurusan Fisika, Fakutas Matematika dan Ilmu Pengetahuan Alam, \\ Universitas Brawijaya, Jalan VeteranMalang 65145, Jawa Timur, Indonesia \\ Alamat korespondensi: tlapailaka@yahoo.com dan ruroh@ub.ac.id
}

\begin{abstract}
Abstrak: Telah dilakukan sintesis dan penumbuhan lapisan tipis PZT di daerah morphotropic phase boundary (MPB) dengan metode sol gel dan teknik pelapisan dengan metode spin coating. Lapisan tipis PZT menunjukkan sifat piezoelektrik maksimum apabila struktur kristalnya membentuk fase perovskite dengan perbandingan tertentu Zirkonium-Titanum di daerah MPB. Tujuan penelitian adalah untuk mengetahui pengaruh penambahan timah hitam terhadap struktur Kristal lapisan tipis PZT. Pengaruh timah hitam dibuat dengan cara menambahkan bahan sumber timah hitam berlebih pada tahap sintesis. Pelapisan larutan gel PZT pada silikon dilakukan dengan teknik spin coating, hasil spin coating dilakukan annealing pada suhu $600^{\circ} \mathrm{C}$ dan dikarakterisasi dengan menggunakan XRD. Analisis XRD pada lapisan tipis PZT dengan variasi penambahan $\mathrm{Pb}$ di daerah MPB menghasilkan struktur polikristalin perovskite. Untuk semua lapisan tipis PZT dengan perbandingan prosentase timah hitam 100:102:104 pada variasi Zirconium-Titanum 52:48 menunjukkan prosentase fase tetragonal perovskite yang lebih besar dibandingkan dengan fase rhombohedral perovskite. Semakin banyak jumlah timah hitam yang digunakan untuk mensintesis PZT maka ada kecenderungan berkurangnya prosentase fase tetragonal atau bertambahnya persentase fase rhombohedral kecuali untuk lapisan tipis PZT dengan perbandingan (102:52:48).
\end{abstract}

Kata kunci: PZT, metode sol gel, polikristalin, struktur kristal

\begin{abstract}
The synthesis and growth of thin-layer PZT in the morphotropic phase boundary (MPB) area have been successfully conducted through the sol-gel method followed by the covering of its layer using the spin coating method. This thin-layer PZT showed its maximum piezoelectric property when the perovskite phase is formed by the crystal structure on the MPB in the ratio of Zr:Ti. The aim of the research is to determine the effect of $\mathrm{Pb}$ on the crystal structure of the thin-layer PZT. The effect of $\mathrm{Pb}$ was prepared by an excessive addition of $\mathrm{Pb}$ during the synthesis process. The spin coating technique was then performed to cover the PZT gel and the results were annealed at $600{ }^{\circ} \mathrm{C}$ prior to its XRD characterization. XRD analysis of PZT showed the formation of polycrystalline perovskite structure. XRD studies also revealed a larger percentage of tetragonal-perovskite phase compared to rombohedral-perovskite phase for all variation of composition. The more the amount of Pb used to synthesize PZT, the greater the tendency of rombhohedral phase formation with the exception for a thin layer PZT with the composition of 102:52:48
\end{abstract}

Keywords: PZT, sol-gel method, polycrystalline, crystal structure

\section{PENDAHULUAN}

Keramik adalah senyawa yang mengandung unsur logam dan non logam. Pengertian proses keramik adalah rangkaian perlakuan-perlakuan secara sistematik sehingga menghasilkan perubahanperubahan dalam aspek fisika dan kimia (Huda \& Hastuti, 2012). Salah satu contoh bahan keramik adalah keramik timbal zirkonat titanat (PZT) yang mempunyai keunggulan dalam sifat polarisabilitas, piezoelektrik, pisoelektrik dan tetapan dielektrik yang tinggi (Chang etal, 2004).

Komposisi PZT yang kaya dengan $\mathrm{PbTiO}_{3}$ adalah struktur tetragonal, sedangkan komposisi PZT yang kaya dengan $\mathrm{PbZrO}_{3}$ adalah struktur rhombohedral. Daerah morphotropic phase boundary (MPB) adalah daerah yang memisahkan fase tetragonal dan rhombohedral, dimana pada daerah ini komposisi dapat terjadi co-eksistensi kedua fase tersebut yang menunjukkan sifat piezoelektrik maksimum (Zhou, 2003).

Bubuk PZT dapat disintesis dengan berbagai macam cara antara lain: reaksi fase padat, kopresipitasi dan sol-gel (Min Oh et al., 2011). Metode sol gel pada umumnya digunakan dalam membuat film tipis keramik dengan luas permukaan besar dan merupakan teknik pembuatan film tipis feroelektrik dan piezoelektrik yang terus dikembangkan. Metode ini mempunyai beberapa keuntungan meliputi: prosesnya yang relatif mudah, kontrol stoikiometri yang baik, dapat diperoleh lapisan yang homogen dengan luas area yang besar, suhu proses yang rendah, dan produk dengan tingkat 
kemurnian yang tinggi. Pada proses sol gel reaksi dapat dikontrol dengan mengatur $\mathrm{pH}$ larutan, jenis penstabil dan prekursor, suhu reaksi, konsentrasi dan parameter lainnya. Pemilihan prekursor dapat mempengaruhi kinetika reaksi kimia yang terjadi, mikrostruktur dan sifat dari produk. Kondisi reaksi sintesis diperlukan untuk hasil yang optimum, sehingga penggunaan penstabil dan modifikasinya berperanan penting.

Teknik pembuatan gel dan lapisan film PZT dengan proses sol gel mulanya dengan menggunakan penstabil larutan metoksi etanol (MOE) dari timbal asetat trihidrat, titanium propoksida dan zirkonium propoksida sebagai rute standar atau dikenal sebagai rute MOE.

Pelarut MOE bersifat teratogenik dan dapat menyebabkan bahaya neurologi dan hematologi pada tingkat ppm, sehingga pada penelitian ini timbal zirkonat titanat dibuat dengan metode sol gel menggunakan penstabil asetil aseton. Asetil aseton adalah reagen pengkelat untuk menekan reaksi hidrolisis yang cepat. Penggunaan asetil aseton menyebabkan larutan tidak peka terhadap kelembaban. Film PZT yang diperoleh dari asetil aseton menunjukkan sifta stabil dan tanpa retak (Etin et al., 2006).

Fase perovskite PZT dengan struktur tetragonal mulai terbentuk pada suhu sekitar $600^{\circ} \mathrm{C}$. Masalah pada saat proses pembakaran berlangsung terjadi penguapan $\mathrm{PbO}$ sehingga lapisan tipis PZT yang dihasilkan tidak akan stoikiometris. Dengan demikian kelebihan jumlah timah hitam diperlukan untuk tercapainya stoikiometri karena sifat lapisan tipis PZT juga akan berubah dengan berubahnya stoikiometris. Jumlah kelebihan timah hitam pada lapisan tipis PZT berpengaruh pada nukleasi dan proses penumbuhan serta sifat elektro mekanis lapisan tipis PZT (Park et al., 2008). Namun, belum ada penelitian sistematis tentang jumlah timah hitam yang diperlukan untuk pembentukan lapisan tipis PZT secara stoikiometri dengan perbandingan $\mathrm{Zr}$ :Ti di daerah MPB. Oleh karena itu perlu mengkompensasi kehilangan timah hitam dengan cara bahan sumber timah hitam yang di tambah secara berlebih pada tahap sintesis dengan metode sol gel.

\section{BAHAN DAN METODE}

Penelitian dilaksanakan di Laboratorium Kimia Anorganik Universitas Brawijaya Malang untuk pembuatan sol gel. Pelapisan material dengan metode spin coating dilakukan di Laboratorium Biofisika Universitas Brawijaya Malang. Karakterisasi lapisan tipis PZT dengan XRD dilakukan di Laboratorium Central Universitas Negeri Sepuluh November Surabaya. Penelitian ini dimulai dari bulan Desember 2012 hingga bulan Mei 2013.

Alat-alat yang digunakan dalam penelitian ini yaitu; satu set komponen refluks, berupa: labu destilasi leher tiga $250 \mathrm{~mL}$, kondensor bola, termometer alkohol $100^{\circ} \mathrm{C}$, pemompa air, Spin Coater VTZ-100, XRD (X-Ray Diffraction), Furnaces (tungku pemanas), Sonicator Branson 2510, oven Memmert UL30, neraca analitik, pipet volum $10 \mathrm{~mL}$, bola hisap, spatula, gelas arloji, corong kaca, krusibel porselen, mikropipet socorex $100-1000 \mu \mathrm{L}$, hot plate stirrer digital cimarec dan magnetic stirrer.

Bahan-bahan yang digunakan dalam penelitian ini yaitu; timbal (II) asetat trihidrat dalam bentuk padatan/serbuk, zirkonium (IV) propoksida dalam bentuk larutan, titanium (IV) propoksida dalam bentuk larutan, asetil aseton, asam asetat, n-propanol, metanol dan silicon wafer.

Sintesis prekusor PZT menggunakan metode sol gel dilakukan dengan variasi penambahan timah hitam yaitu 0,2 dan $4 \% \mathrm{~b} / \mathrm{v}$. Jumlah bahan yang digunakan untuk mensintesis setiap PZT dapat ditunjukkan pada Tabel 1. Tahapan sintesis prekursor PZT dapat di lihat pada Gambar 1.

Tabel 1. Jumlah variasi bahan

\begin{tabular}{|c|c|c|c|}
\hline & \multirow{2}{*}{$\begin{array}{c}\text { Perbandingan } \\
\text { Pb:Zr:Ti }\end{array}$} & Massa & \multicolumn{2}{|c|}{ Polume larutan $(\mathbf{m L})$} \\
\cline { 3 - 4 } & $\mathbf{( g )}$ & $\mathbf{Z r}$ & $\mathbf{T i}$ \\
\hline $100: 52: 48$ & 0,341 & 0,207 & 0,119 \\
$102: 52: 48$ & 0,347 & 0,207 & 0,119 \\
$104: 52: 48$ & 0,354 & 0,207 & 0,119 \\
\hline
\end{tabular}

Larutan PZT yang telah dibuat kemudian dilapiskan di atas substrat Silikon (silicon wafer) dengan menggunakan spin coater. Silikon dibersihkan dengan menggunakan metanol dan dimasukkan ke dalam sonicator selama 10 menit. Silikon yang telah dibersihkan lalu dikeringkan dengan menggunakan oven yang diatur pada suhu $100^{\circ} \mathrm{C}$ selama 15 menit. Substrat diletakkan di atas reactor spin coater dengan menggunakan perekat, lalu dilakukan penetesan larutan PZT. Volume total larutan prekursor PZT yang digunakan sebanyak $300 \mu \mathrm{L}$. Reactor spin coater dijalankan dan diset dengan kecepatan SPD1=500 rpm, SPD2=3000 rpm selama 60 detik. Lapisan PZT yang terbentuk di atas substrat silikon dipanaskan dalam tanur (annealing) selama 4 jam. Pada 1 jam pertama suhu dinaikan secara bertahap hingga mencapai $600^{\circ} \mathrm{C}$, selama 2 jam berikutnya suhu dipertahankan pada $600^{\circ} \mathrm{C}$ dan pada 1 jam terakhir suhu diturunkan secara bertahap hingga mencapai suhu ruang kembali. Pembuatan lapisan tipis ini dilakukan untuk semua variasi pembuatan PZT.

Sampel atau lapisan yang sudah dipanaskan kemudian dikarakterisasi menggunakan XRD dengan posisi sudut $2 \theta$ diatur pada $15-80^{\circ}$ dengan waktu scan tiap bagian sebesar 1 menit. Hasil yang diperoleh berupa difraktogram dengan perbandingan intensitas

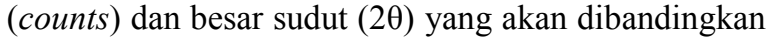
dengan PZT standar JCPDS data no 33-784 karakterisasi dengan XRD dilakukan untuk semua lapisan tipis PZT dengan variasi penambahan timah hitam. 


\section{Larutan Titanium (IV) propoksida}

- Ditambahkan larutan asetil aseton Diaduk pada $80^{\circ} \mathrm{C}$ selama 10 menit

\section{Sub-produk 1}

-Ditambahkan timbal asetat $0,341 \mathrm{~g}$

- Ditambahkan asam asetat $1 \mathrm{~mL}$

- Ditambahkan propanol $1 \mathrm{~mL}$

- Diaduk pada $120^{\circ} \mathrm{C}$ selama 10 menit

\section{Sub-produk 1}

-Ditambahkan Zirkonium(IV)propoksida 0,207 mL -Diaduk pada $80^{\circ} \mathrm{C}$ selama 4 jam

-Ditambahkan larutan gel yang encer

\section{Gel berwarna kuning}

Gambar 1 Diagram alir sintesis PZT

\section{HASIL DAN PEMBAHASAN}

Karakterisasi pengaruh penambahan timah hitam terhadap struktur kristal di daerah MPB dilakukan dengan menggunakan XRD. Hasil XRD lapisan tipis PZT dengan perbandingan Zr:Ti (52:48) dan variasi penambahan timah hitam 0,2 dan $4 \%$ ditunjukkan pada Gambar 2.

Puncak-puncak yang muncul pada difraktogram XRD untuk semua lapisan tipis dibandingkan dengan standar JCPDS data no 33-784. Hasilnya mengindikasikan bahwa lapisan tipis PZT yang dihasilkan memiliki struktur perovskite dengan orientasi bidang kristal ( $h k l)$ menunjukkan (001), (110), (111), (200), (210), (211) dan (002). Munculnya sebaran orientasi bidang kristal ini menunjukkan bahwa lapisan tipis PZT yang dihasilkan memiliki struktur polikristalin. Intensitas masing-masing orientasi bidang kristal lapisan tipis PZT pada tiap variasi perbandingan timah hitam relatif tidak memperlihatkan perbedaan. Berdasarkan difraktogram lapisan tipis PZT, maka pada lapisan tipis PZT (104:52:48) terdapat fase pyrochlore dan zirkonium oksida yang menunjukkan bahwa semakin banyak jumlah timah hitam yang digunakan, maka akan mengurangi prosentase fase perovskite, dimana nilai prosentase dari fase perovskite dapat ditentukan dengan menggunakan persamaan (Bhatt et al., 2010).

$\%$ perovskite phase $=\frac{I_{(110)}}{I_{(110)}+I(\text { pyro })}$

Dimana I(110) adalah intensitas (counts) pada puncak 110 dan I(pyro) adalah intensitas (counts) pada puncak pyrochlore.

Nilai prosentase fase perovskite untuk setiap penambahan timah hitam dapat ditunjukkan pada Gambar 3.

Berdasarkan Gambar 3 maka nilai prosentase perovskite untuk PZT (100:52:48) dan PZT (102:52:48) sebesar $100 \%$ sedangkan prosentase perovskite untuk PZT (104:52:48) sebesar 82,36\%. Dengan demikian, maka semakin banyak timah hitam yang digunakan maka akan memunculkan fase

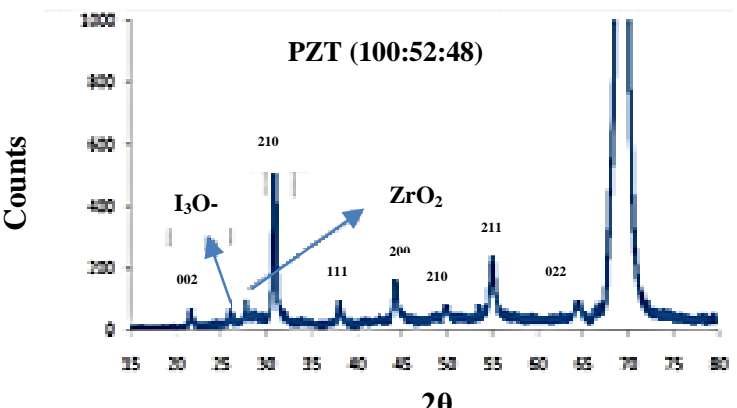

20
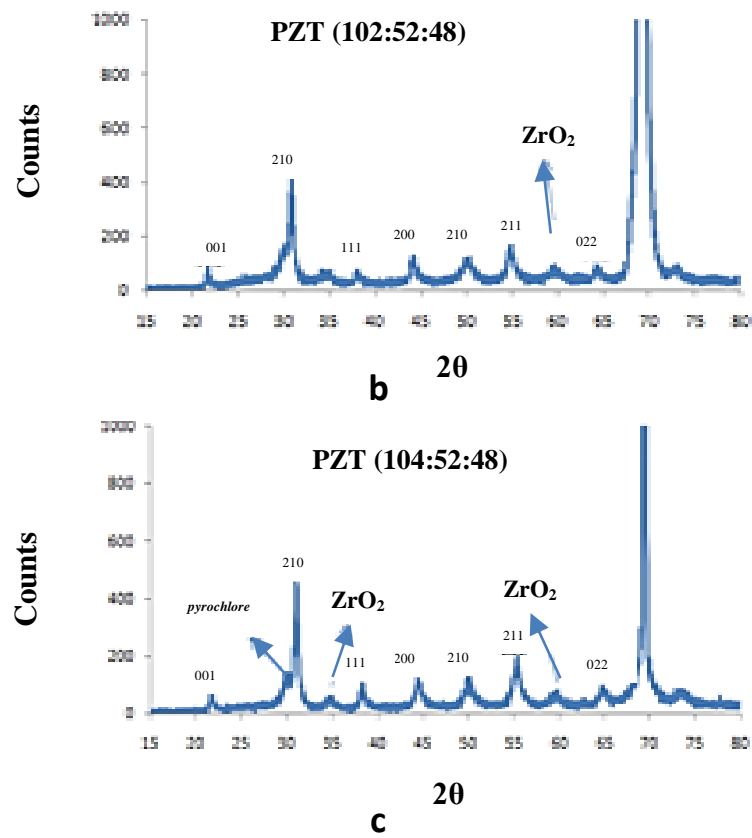

Gambar 2. Difraktogram struktur kristal lapisan tipis PZT variasi penambahan timah hitam dengan perbandingan $\mathrm{Zr:Ti}=52: 48$. (a) 100:52:48, (b) 102:52:48 dan (c) 104:52:48

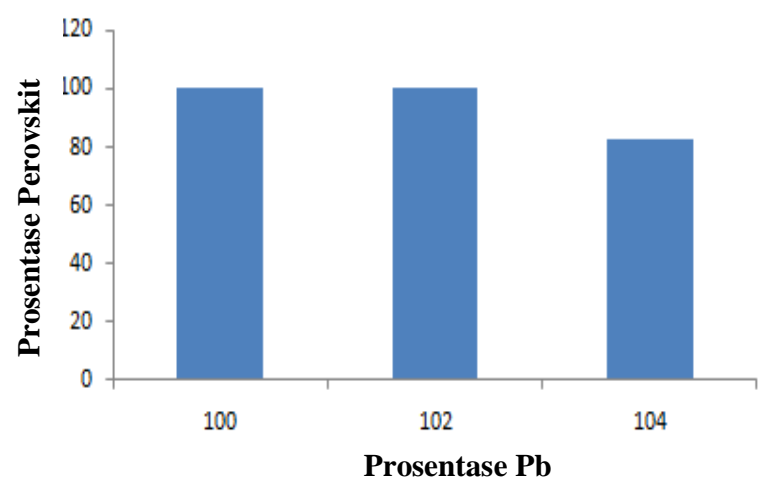

Gambar 3. Prosentase fase perovskit dengan variasi $\mathrm{Pb}$ $(100,102,104)$ pada rasio $\mathrm{Zr}: \mathrm{Ti}(52: 48)$.

pyrochlore yang menyebabkan prosentase fase perovskite semakin berkurang.

Variasi penambahan timah hitam dapat mempengaruhi fase kristal perovskite yang dihasilkan apakah berbentuk tetragonal perovskite atau rhombohedral perovskite. Untuk menentukan lapisan 
tipis yang dihasilkan membentuk fase tetragonal perovskite atau fase rhombohedral perovskite maka dilihat pola XRD pada daerah dengan $2 \theta 44,45$ dan 46 derajat yaitu mewakili (002)T, (200)R dan (200)T.

Prosentase rhombohedral ditentukan dengan menggunakan persamaan (Bhatt et al., 2010):

$$
\mathrm{P}_{\mathrm{R}}=\frac{I_{\mathrm{R}(200)}}{I_{R(200)}+I_{T(200)}+I_{T(002)}}
$$

Dimana $P_{R}$ adalah prosentase rhombohedral, $\mathrm{I}_{\mathrm{R}(200)}$ adalah intensitas pada puncak 200 (20 sebesar $\left.45^{\circ}\right), \mathrm{I}_{\mathrm{T}(200)}$ adalah intensitas pada puncak 200 (20 sebesar $46^{\circ}$ ) dan $\mathrm{I}_{\mathrm{T}(002)}$ adalah intensitas pada puncak 002 (2 $\theta$ sebesar $44^{\circ}$ ), untuk prosentase fase tetragonal dapat dihitung dengan menggunakan persamaan:

$$
\mathrm{P}_{\mathrm{T}}=100-\mathrm{P}_{\mathrm{R}}
$$

Nilai prosentase fase tetragonal dan fase rhombohedral untuk setiap penambahan $\mathrm{Pb}$ dapat ditunjukkan pada Gambar 4.

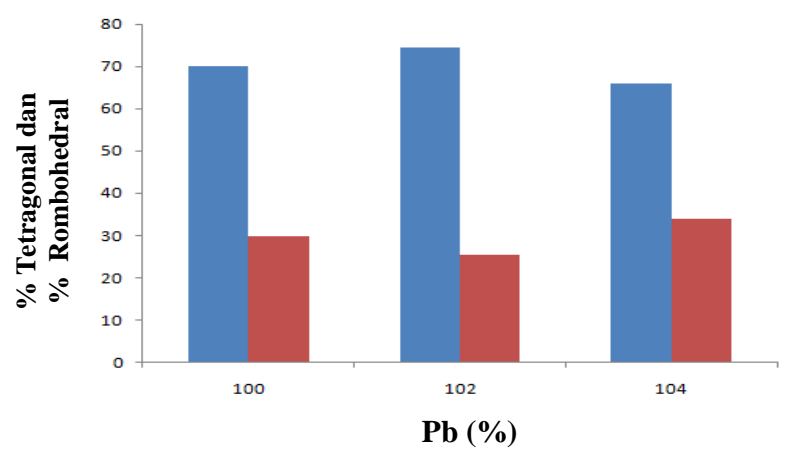

Gambar 4. Prosentase fase tetragonal dan fase rhombohedral.

Berdasarkan Gambar 4 maka nilai prosentase fase tetragonal untuk PZT (100:52:48), PZT $(102: 52: 48)$ dan PZT $(104: 52: 48)$ berturut-turut sebesar 70,06, 74,49 dan 66,00\%, sedangkan nilai prosentase fase rhombohedral untuk PZT (100:52:48), PZT (102:52:48) dan PZT (104:52:48) berturut-turut sebesar 29,94, 25,51 dan 44,00\%. Dengan demikian maka untuk semua PZT baik PZT (100:52:48), PZT (102:52:48) dan PZT (104:52:48) memiliki prosentase fase tetragonal perovskite yang lebih besar dibandingkan dengan fase rhombohedral perovskite. Semakin banyak jumlah $\mathrm{Pb}$ yang digunakan untuk mensintesis PZT maka ada kecenderungan berkurangnya prosentase fase tetragonal atau bertambahnya prosentase fase rhombohedral kecuali untuk lapisan tipis PZT (102:52:48). Hal ini diduga bisa disebabkan oleh suhu annealing yang berpengaruh terhadap pembentukan fase tetragonal dan fase rhombohedral, dimana untuk setiap variasi penambahan timah hitam diperlukan suhu annealing yang berbeda karena temperatur berpengaruh juga terhadap penumbuhan fase kristal pada lapisan tipis PZT.

\section{KESIMPULAN}

Berdasarkan analisis XRD pada lapisan tipis PZT dengan variasi penambahan timah hitam di daerah MPB menghasilkan struktur polikristalin perovskite. Untuk semua lapisan tipis PZT baik PZT (100:52:48), PZT (102:52:48) dan PZT (104:52:48) memiliki prosentase fase tetragonal perovskite yang lebih besar dibandingkan dengan fase rhombohedral perovskite. Semakin banyak jumlah timah hitam yang digunakan untuk mensintesis PZT maka ada kecenderungan berkurangnya prosentase fase tetragonal atau bertambahnya prosentase fase rhombohedral kecuali untuk lapisan tipis PZT (102:52:48).

\section{UCAPAN TERIMA KASIH}

Kami mengucapkan terima kasih kepada Program PHKI tema B melalui DIPA Universitas Brawijaya Tahun 2011 yang telah memberikan dana, sebagian untuk penelitian lapisan tipis PZT ini.

\section{DAFTAR PUSTAKA}

Bhatt, S. S., Chaudhry, S.C., Sharma, N \& Gupta, S. (2010). Synthesis of nano crystalline spatulae of lead zirconate titanate $\left(\mathrm{PbZr}_{0,52} \mathrm{Ti}_{0,48} \mathrm{O}_{3}\right)$. Natural Science, 2(1), 12-17.

Chang, Tien-I., Huang, Jow-L., Lin, Jen-F., Chen, Bing-H., Wu, L., Lin, Hong-P \&Lu, HorngHwa (2004). Effect of drying temperature on the characteristics oflead zirkonium titanat powders prepare by sol-gel process, Material Transactions, 45, 3150-3155.

Etin, A., E, Gennady., Shter., Baltianski, S \& Grader, G.S. (2006). Controlled elemental depth profile in sol-gel-derived PZT films, The American ceramic society,89(8), 2387-2393.

Hikam, M., Irzaman., Darmasetiawan, H \& Yogaraksa T. (2002). Studi kekristalan PZT yang disiapkan dengan pelapisan putar (Spin Coating). Indonesian Journal of Material Science, 4, 16-19. ISSN 1411-1098.

Huda, M \& Hastuti, E. (2012). Pengaruh temperatur pembakaran dan penambahan abu terhadap kualitas batu bata, Jurnal Neutrino, 4(2), 142152 Liu, W \& Zhu, W. (2000).

Liu, W \& Zhu, W. (2000). Preparation and orientation control of $\mathrm{Pb}_{1,1}\left(\mathrm{Zr}_{0,3} \mathrm{Ti}_{0,7}\right) \mathrm{O}_{3}$ thin films by a modified sol-gel process, Microelectronics Center, School of Electrical and Electronic Engineering, Nanyang Technological UniÍersity, Singapore.

Min oh, S., Kang, Min-G., Ho do, Y., Kang, C.Y \& Yoon, S.J. (2011), Fabrication of $1 \mu \mathrm{m}$ thickness lead zirkonium titanate films using 
poly ( $N$-Vinylpyrrolidone) added sol gel method. Regular Paper Transactions on Electrical And Electronic Materials, 12(5), 222-225.

Park, Chee-S., Lee, Sung-M \& Kim, Hyoun-E. (2008), Effects of excess $\mathrm{PbO}$ and $\mathrm{Zr} / \mathrm{Ti}$ ratio on microstructure and electrical properties of PZT films, Department of Materials Science and Engineering, Seoul National University,
Seoul-Korea.

Tas, A.C. (1999). Preparation of lead zirconate titanate $\left(\mathrm{Pb}\left(\mathrm{Zr}_{0,52} \mathrm{Ti}_{0,48}\right) \mathrm{O}_{3}\right)$ by homogeneous precipitation and calcination. The American ceramic society, 82 (6)1582-1584

Zhou, D. (2003). Experimental investigation of non linear constitutive behavior of PZT piezoceramics. Disertasi Institut Material Forschung, Karishura University, Karishura. 